\title{
Deir el-Bersha e a "democratização": Uma nova maneira de compreender os Textos dos caixóes e o sistema nomárquico
}

\author{
Cintia Alfieri Gama-Rolland*
}

Willems, H. Historical and Archaeological Aspects of Egyptian Funerary Culture. Religious Ideas and Ritual Practice in Middle kingdom Elite Cemeteries. Culture \& History of the Ancient Near East, v. 73. Leiden, Boston: E. J. Brill, 2014.

Esse livro, publicado em 2014, na série Culture \& History of the Ancient Near East, volume 73, pelo tradicional editor de livros de egiptologia E. J. Brill é o mais recente dentre os escritos por Harco Willems. O autor é professor e pesquisador na Universidade Católica de Leuven - Lovaina - na Bélgica. O livro é uma tradução, com atualizaçôes de certos conceitos, da edição francesa chamada Les Textes des sarcophages et la démocratie: éléments d'une histoire culturelle du Moyen Empire Égyptien, de 2008.

$\mathrm{O}$ autor é um especialista inconteste no que concerne ao Médio Império (XI e XII dinastias, c. 2065-1781 a.C.) e aos Textos dos caixóes, tema que estuda desde seu doutorado. Atualmente, ele chefia as escavaçôes do sítio de Deir el-Bersha, local onde estão as tumbas em hipogeu dos nomarcas, dentre eles a do celebre Djehutihotep - 17L20/1 (antigo número 2) -, grande chefe (nomarca) do nomo da lebre, que serviu durante os reinados de Amenemhat II, Senusret II e Senusret III.

O livro em francês e, consequentemente, sua tradução são provenientes de uma série de quatro conferências dadas pelo autor na École Pratique des Hautes Études, em maio de 2006, a convite de Christiane Zivie-Coche. $\mathrm{O}$ fato de esse livro ser a publicaçáo de quatro conferências lhe confere um aspecto narrativo e analítico bastante claro, sendo uma síntese dos trabalhos empreendidos pelo autor até o presente.

O primeiro capítulo trata da cultura nomarcal, abordando de uma maneira explicativa os aspectos políticos, administrativos, sociais e religiosos dessa categoria social que tem seu momento forte na história egípcia durante o Médio Império. Esse capítulo, mais voltado para o sistema político e administrativo, trata também da origem da organização do estado egípcio em nomos, durante o Antigo Império (c. 2670-2195 a.C.), e a continuaçáo desse sistema e seus meios administrativos regionais durante o Pri-

DOI - http://dx.doi.org/10.1590/2237-101X0173215

* Doutora em Religião e Sistemas de Pensamento pela École Pratique des Hautes Études — Paris. E-mail: gamacintia@hotmail.com. 
meiro Período Intermediário (c. 2195-2065 a.C.) e Médio Império. Por meio do estudo da cultura nomarcal o autor apresenta toda a organização do estado egípcio fazendo paralelos entre a política, a administração e a história egípcia.

Ainda nessa parte é analisado o que representa o título de nomarca para os egípcios antigos, suas funçóes e atributos, em comparação com as interpretaçóes dadas pela egiptologia. É tratado também da tradução desse termo originalmente grego e, se é correto usarmos o termo nomarca ou não.

Por sinal, a discussão acerca do termo nomarca é um dos pontos altos desse capítulo, pois se as primeiras partes contextualizam o âmbito de ação dessa categoria social, é durante a análise do termo que há uma revisão bibliográfica dos estudos mais recentes sobre o tema e a apresentação de um vasto conjunto de fontes epigráficas em que o termo egípcio hr.y.w-tp '3 $n$ spz.t ou hrr.y.w-tp ' 3 é mencionado.

O primeiro capítulo estabelece, assim, as bases tanto informativas quanto críticas sobre a política egípcia antiga, tendo como foco uma categoria social precisa e a maneira como essa se inseria na sociedade egípcia como um todo. Se essa primeira parte é mais voltada para as fontes epigráficas, a segunda apresenta os principais sítios e trabalhos arqueológicos referentes ao Médio Império. Mesmo se centrado no trabalho empreendido pelo autor em Deir el-Bersha, Harco Willems passa em revista o histórico das escavaçóes realizadas em sítios ligados ao poder nomarcal.

O sítio de Deir el-Bersha, localizado no
Médio Egito, é conhecido por ter funcionado como pedreira, e, sobretudo, por ter sido, durante o Médio Império, a sede do cemitério dos nomarcas do XV nomo do Alto Egito, mas ele também contém sepulturas que vão do Antigo Império até o Período Greco-Romano (332 a.C-395 d.C.). Trata-se assim de um dos grandes locais para o estudo do poder nomárquico. $\mathrm{O}$ projeto da Universidade Católica de Leuven, The Dayr el-Barsha Project, começou em 2002 e as escavações continuam até hoje. Os diversos artigos oriundos das campanhas de escavações são publicados anualmente em revistas especializadas e trabalhos de pesquisa de maior fôlego são realizados sob a forma de teses, como a defendida em novembro de 2015 por Athena Van der Perre sobre a pedreira de calcário de Deir el-Bersha usada na época amarniana (1350-1333 a.C.). Ao tratar dessa localidade, o autor aproveita para fazer uma revisão dos trabalhos anteriores aos de sua equipe, comparando o que foi feito por outros e suas respectivas conclusóes com a pesquisa empreendida atualmente. Essa revisão dos estudos tanto de Deir el-Bersha quanto de outras cidades do Médio Império nos fornece uma imagem bastante completa do período estudado, bem como das abordagens arqueológicas de cada época.

$\mathrm{Na}$ parte final do segundo capítulo, após descrever as descobertas de 2006, o autor trata de uma questão muito em voga nos estudos atuais sobre a religião egípcia, a paisagem ritual. Com seu trabalho, o autor mostra como os cemitérios nomarcais se desenvolveram tornando-se grandes paisagens processionais para o culto do governador lo- 
cal. É explicado que as rotas de acesso do cemitério deviam servir como vias processionais para uma cerimônia em que a linhagem dos governadores era cultuada. Sendo que o eixo principal do mesmo liga as tumbas dos nomarcas a capelas cultuais. Para endossar essa hipótese o autor apresenta mapas do cemitério e analisa tanto o alinhamento da via principal quanto o das tumbas e a decoração delas. Tudo isso comparando Deir el-Bersha a outros sítios da mesma época, como Qaw el-Kebir, Qubbat el-Hawa e Deir el-Bahari.

Em seguida, para melhor compreender o que a paisagem arqueológica deixa evidente, Harco Willems faz uso da epigrafia, estudando os textos autobiográficos. Ele nota também que o sistema de culto dos governadores de Deir el-Bersha não é idêntico ao de Balat e de Elefantina, mas que em linhas gerais a procissão e, consequentemente, o culto aos governadores se ordenam entre dois polos formados pelas capelas de culto dos governadores e suas tumbas.

Por fim, é evidenciado que o culto aos governadores é uma prática religiosa com certa especificidade, em que homens com poderes políticos ou pertencentes às altas esferas da sociedade ocupavam um lugar particular no pensamento religioso da população, sem serem divindades, mas como um chefe morto venerado.

O terceiro, mais longo e completo dos capítulos, dividido em seis subpartes, é aquele que trata da "democratização" dos textos funerários. Com o intuito de estabelecer o histórico desse tema, antes de desconstruí-lo, o autor inicia sua análise apresentando os fatores e autores que desenvolveram ou fazem uso da teoria da "democratização" ou "demotização". Nessa primeira parte, o autor faz um belo exercício teórico inserindo os criadores da teoria da "democratização" em seus contextos históricos e políticos, mostrando, assim, em que medida pontos de vista pessoais bem como o momento histórico vivido por cada autor influenciou na sua forma de abordar a religião egípcia antiga e suas transformaçóes.

Em seguida, para iniciar a desconstrução da teoria da "democratização", o autor trata das transformações passadas pelo equipamento funerário durante o Primeiro Período Intermediário e Médio Império, para depois tratar dos Textos dos caixóes pelo viés da demografia. A análise demográfica é constituída por quatro elementos: o estabelecimento da população egípcia durante o Médio Império, a quantificação dos caixões decorados de el-Bersha, de Beni Hasan e de Assiut. Já nesse momento, ao cruzar os dados referentes ao número de habitantes do Egito no Médio Império com o de caixóes decorados, o autor evidencia o fato de que possuir esquifes e, ainda mais, aqueles decorados, era algo extremamente elitista, longe do pregado pelos adeptos da "democratização". Nas palavras do próprio autor: "Having access to Coffin Texts was about as exceptional to the Middle Kingdom Egyptian as it would be today to possess a Rolls Royce".

Após constatar o uso restrito dos ataúdes decorados e consequentemente dos Textos dos caixóes, o autor procede a um estudo ge-

\footnotetext{
1 "Ter acesso aos Textos dos caixóes era táo excepcional no Médio Império egípcio como seria hoje possuir um Rolls Royce."
} 
ográfico da distribuição dos caixôes decorados e dos textos inscritos neles, chegando à conclusão de que o ponto de partida dessa tradição funerária das elites (a inscrição de textos funerários nas paredes de seus caixões) teria sido o scriptorium de el-Ashmunein, local de onde difundiram-se os textos funerários não apenas para Tebas e Deir el-Bersha, mas também para as regióes nomarcais mais afastadas do Médio Egito. Com isso, o autor começa a estabelecer o epicentro de sua teoria, isto é, que o uso dos Textos dos caixóes está intimamente ligado à cultura nomarcal e de forma alguma às esferas da população sem relação com os governadores ou poder locais, fazendo com que esse tipo de texto funerário caia em desuso com a decadência do poder dos nomarcas.

$\mathrm{Na}$ última parte desse capítulo, para fortalecer sua teria, Harco Willems associa os Textos dos caixóes às cartas aos mortos, estudando especificamente os spell 30-41, 131-146, 149 e 312. Mostrando, assim, que uma nova visão do pós-vida proveniente das camadas dirigentes, mas não faraônicas, ganha espaço no domínio funerário. Uma visão do além que reproduz o mundo dos vivos e diversos aspectos da vida quotidiana da elite. Assim, os Textos dos caixóes, além de não serem uma difusão de privilégios reais ao povo, são uma criação da elite para a elite.

Além dos três capítulos, o livro tem anexos de muito interesse, como uma lista atualizada dos caixóes decorados do Médio Império, a maioria deles inédita, e um epílogo que conta com informaçóes referentes às novas descobertas egiptológicas associadas à pesquisa do autor.
Trata-se de um livro extremamente inovador por diversas razóes. Primeiramente, ele permite restituir a organização político-administrativa do Egito de suas origens até o Médio Império, passando por períodos complexos como o Primeiro Período Intermediário. Nele são também apresentados os resultados das escavações de Deir el-Bersha com a sua nova paisagem ritual, mostrando que o cemitério é mais vasto do que se pensava e que se organizava como um local de culto do poder nomárquico.

Mas o fator essencial e o maior de todos os avanços oferecidos por essa obra é o fato de questionar uma teoria aceita desde o início do século XX pela egiptologia, conhecida como "democratização" ou "demotização" das práticas funerárias. Esse questionamento bastante convincente se dá por meio do estudo aprofundado dos Textos dos caixóes, posicionando-os em seus contextos histórico, político, administrativo e cultural do Primeiro Período Intermediário e Médio Império, e pela comparação com outras fontes epigráficas, como as cartas aos mortos e autobiografias da mesma época. Harco Willems consegue, assim, mostrar de maneira persuasiva que os Textos dos caixóes não eram tão comuns como se imaginou e que sua difusão foi extremamente restrita, não sendo o reflexo de uma religião funerária praticada por todas as categorias sociais egípcias, mas apenas pela alta elite do Médio Império, os nomarcas.

Por meio do questionamento da teoria da difusão da religião funerária dos reis a toda sociedade, dos Textos das pirâmides até o Livro dos mortos (a chamada "democratiza- 
ção"), o autor traz uma análise das correntes de pensamento da egiptologia. Deixando evidente as influências da sociedade contemporânea sobre os egiptólogos, Willems mostra que por vezes o contexto de vida de certos autores e suas opinióes políticas acabam por influenciar suas análises do passado egípcio. Com isso, ele abre uma via inovadora de estudos que concernem ao Médio Império, tornando-se uma leitura essencial para aqueles que desejam estudar tanto a religiấo funerária egípcia antiga quanto os desenvolvimentos subsequentes aos Textos dos caixóes. Além do mais, esse texto, de uma clareza e método irrepreensíveis, é um exemplo de como desenvolver uma pesquisa aliando diversas fontes e diversas abordagens sem a alienaçáo de um estudo puramente religioso, político ou social. 